\title{
Essay
}

\section{The Research Dynamic: A Professional Development Model for Secondary School Science Teachers}

\author{
Philip M. Silverman
}

Genetic Models of Disease Research Program, Oklahoma Medical Research Foundation, Oklahoma City, OK 73104

Submitted March 27, 2008; Revised December 2, 2008; Accepted February 16, 2009

Monitoring Editor: Nancy Moreno

\begin{abstract}
This essay summarizes the author's 10 years of experience at the Oklahoma Medical Research Foundation mentoring secondary school science teachers during 8-wk Summer Research Institutes. The summary is presented as a learning model, which we call the research dynamic. This model consists of three interlocked components: specified ignorance, peer interactions, and gateway experiments. Specified ignorance is based on the work of the sociologist Robert K. Merton. It is essentially the art of highlighting what is not known about a phenomenon but must become known for further progress. In practice, specified ignorance is framed as a hypothesis, a prediction, or a question. It is commonly the outcome of peer interactions, which are the second essential component of the research dynamic. Peer interactions are the inevitable outcome of having teachers work together in the same laboratory on related research topics. These topics are introduced as gateway experiments, the third component. The most important attribute of gateway experiments is their authenticity. These experiments, when first carried out, opened new scientific vistas. They are also technically, conceptually, and logically simple. We illustrate the research dynamic with a line of seminal experiments in biochemical genetics. We provide evidence that the research dynamic produced significantly positive effects on teachers' confidence in their professional preparedness.
\end{abstract}

\section{INTRODUCTION}

This essay distills the author's 10 years as a mentor for rural high school science teachers in the Oklahoma Science Project (OSP). The core element of the OSP was an 8-wk summer research experience at the Oklahoma Medical Research Foundation intended to enhance rural teachers' laboratory skills and confidence (Leslie, 2001). OSP applicants, although dedicated professionals with excellent records of attending courses, institutes, workshops, and other activities related to professional development, including in some cases national certification, generally lacked significant laboratory experience or the more crucial experience of thinking like a scientist. It soon became clear that the OSP would have to address more than technical skills. We would have to introduce scientific habits of thought to intelligent and willing but largely naïve individuals. This new perspective

DOI: $10.1187 /$ cbe.08-03-0015

Address correspondence to: Philip M. Silverman (silvermanp@ omrf.org). motivated careful thought about the essential features of how science is actually done. As this occurred, the OSP evolved into the professional development model described here and which we refer to as the research dynamic.

The OSP was originally based on the author's intuitive sense as a professional scientist that teachers should be comfortable with both the conceptual and technical content of key scientific discoveries and with the cognitive practices that scientists used when they made those discoveries (Silverman, 2003). This was essentially an historical perspective meant to engage science teachers in authentic (re)discovery. The author, as mentor, would provide technical guidance with explicit attention to the cognitive context of experiments when they were first done.

This last point is worth elaboration. Schwartz et al. (2004) have convincingly argued that for teachers and students to understand the nature of science, broadly defined, inquiry alone is insufficient, i.e., doing experiments does not necessarily illuminate the underlying epistemology. Rather, Schwartz et al. (2004) concluded that the cognitively important features of science included under the broad topic 
"nature of science" must be explicitly addressed, preferably in concert with inquiry, but in any case explicitly.

What are these cognitively important features? To find out, Schwartz and Lederman (2007) surveyed 24 professional scientists from several disciplines about their views of the nature of science. Notwithstanding considerable differences in detail, there was broad agreement that scientific knowledge and the process by which that knowledge is acquired are "tentative," "empirical," "theory-laden," and "creative" (Schwartz and Lederman, 2007). All true, to be sure, but such descriptors are not particularly useful formative guides to how an effective professional development program might operate.

\section{SPECIFIED IGNORANCE AND PEER INTERACTIONS}

As operational criteria, I found much more useful the three "cognitive and social patterns in the practice of science" described by the sociologist Robert K. Merton (Merton, 1987). Merton was not addressing educational issues but rather what professional scientists actually do when they do science. The first practice is to establish a phenomenon as an empirical fact suitable for scientific analysis. An example would be phenotypic variation within species populations, a cornerstone of evolutionary thought and easily verified. The second practice is to choose the optimal experimental system with which to study the phenomenon. (Merton refers to "strategic research materials"; biologists often use "model organisms.") If the goal is to study the origin of intraspecies variation, pea plants á la Mendel would be a better model organism than whales and, at a certain level of generality, bacteria would be more useful than pea plants. Merton called the third and most important "the cognitively consequential practice" of specifying ignorance, which can be thought of as the art of highlighting what is not known about a phenomenon but must become known for further progress. In practice, specified ignorance may be framed as a hypothesis, a prediction, or a question.

Interestingly, specified ignorance is often mentioned by scientists and educators. Richard Feynman, the physicist and renowned teacher, referred to "... the great value of a satisfactory philosophy of ignorance" (Feynman, 1998, p. 28). The biologist Joshua Lederberg suggested “... ignorance... rather than knowledge as the terrain for learning and discovery" (Witte, 2008). James Seago, discussing the role of research in undergraduate institutions, also referred to specified ignorance using the phrase "the frontier of knowledge" (Seago, 1992).

In practice, specified ignorance almost always entails ongoing peer interactions to decide where the frontier of knowledge lies and what must be done to push it back. In the OSP, peer interactions were virtually guaranteed by the practice of having teachers work together in the same laboratory on similar research projects. The result was almost continuous discussion not only among teachers but also between teachers and project staff. Invariably, these reflective discussions included issues related to students and classrooms.

At its present state of evolution, the research dynamic is composed of three operational elements: specified igno- rance, peer interactions, and gateway experiments (which will be discussed later). Importantly, specified ignorance and peer interactions are roughly equivalent to the broadly acknowledged features of the "nature of science" revealed in the survey by Schwartz and Lederman (2007). Thus, specified ignorance through peer interactions presupposes that science is empirical; that experimental data are tentative to one degree or another; that in consequence they usually need to be interpreted; that interpretations are theory-laden and consequently negotiated; and that negotiated meaning is a prerequisite for specified ignorance and hence for determining what the next experiments should be (Schwartz et al., 2004). This equivalence validates the use of Merton's three operational practices in an educational context.

The research dynamic depends critically on a scientist/ mentor, whose principal pedagogical task is to guide, but not direct, teachers' research activities and to provide intellectual context. The essential feature of teacher-mentor interactions is reciprocity. Each party must be acknowledged as an expert, albeit in different subjects directly related to science education. The scientist/mentor uses his or her professional experience to convey to teachers the essential features of the research dynamic while accommodating each teacher's interests, abilities, and learning preferences, just as the teachers must accommodate diversity in their classrooms. The teachers then have the opportunity to shape the research dynamic according to their requirements as educators. This reciprocity differentiates interactions between scientist and teacher from those between scientist and graduate student: the teachers are already professionals.

\section{GATEWAY EXPERIMENTS}

If our goal is to familiarize secondary school science teachers with the nature and practice of science, it is important to consider carefully how to select the proper experiments. Contemporaneous, "cutting-edge" research is what excites working scientists but may not be entirely appropriate, because the precollege science classroom will almost certainly lack even the basic necessities to do such research, and students and teachers alike will lack essential background. Experiments should certainly engage teachers in significant and fundamental problems, but more important than immediacy and relevance are technical, logical, and conceptual clarity. Morris Shamos has pointed out that these attributes are clearest at the origins of a discipline, before the knowledge base becomes massive and hyper-specialized (Shamos, 1995, p. 199). The same point was made by the science writer George Johnson. Whereas contemporary research is often carried out by research teams as large as corporations, until recently, seminal experiments were carried out by one or two scientists working on a tabletop with perhaps a slide rule for computation (Johnson, 2008, p. xi). We refer to such experiments as gateway experiments. By their nature, gateway experiments not only capture the essential features of a discipline but also highlight the ordinary and extraordinary qualities of the people who first did them. Egan (1997) (p. 222) has pointed out the pedagogical value of personalizing scientific accomplishment to adolescents.

The historical aspects of a gateway approach are finding their way into the mainstream of educational theory (Egan, 
1997; Donovan and Bransford, 2005, pp. 573-574), notwithstanding a deep resistance to using such an approach as a pedagogical tool in precollege science instruction (e.g., Duschl, 1989). Our experience has been that teachers respond well to the gateway approach (McCarty, 2003), largely because it is based on authentic, historically grounded experiments, as opposed to sterile textbooks and contrived laboratory exercises. We show below that the approach generally increases teachers' confidence in their preparedness to teach science effectively. Others have successfully tied an historical approach to contemporaneous analytical methods (Pedulla et al., 2003; Hanauer et al., 2006), although this may not always be possible.

Carried over to the classroom, gateway experiments could have pedagogical value as a lever to reconfigure the central concepts around which students organize their knowledge. We all tend to organize information in a manner that fits comfortably with our assumptions about the world. When those assumptions later prove to be wrong, as they often do, the result is confusion about and distrust of how knowledge, including scientific knowledge, is acquired and used (Bloom and Weisberg, 2007). It is well established that students bring to the classroom a remarkable body of misinformation that is notoriously difficult to change (Posner et al., 1982; Clough and Wood-Robinson, 1985; Carey, 1986; Kindfield, 1991; Pine et al., 2001; Bloom and Weisberg, 2007). In a recent interview, the physicist Lawrence Krauss (www.seedmagazine.com/news / 2007/12/natalie_jeremijenko_lawrence_k.php) defined the core scientific experience this way: ". . . to have some cherished notion that you absolutely believe to be true proved false." Students might accomplish this through gateway experiments while guided by confident and knowledgeable teachers.

\section{SUMMER RESEARCH INSTITUTES}

The critical structural component of the OSP was the Summer Research Institute (SRI), an 8-wk research experience for selected secondary school science teachers at the Oklahoma Medical Research Foundation. Each SRI accepted four to six teachers. SRIs were set up so that teachers acquired enough technical skill during the first week to focus thereafter on using those skills to pose and answer specific questions within the framework of the research dynamic. The SRIs were located in laboratory space occupied exclusively by the teachers and equipped for their work. The author as scientist/mentor and other project staff were present or available full time for the entire $8 \mathrm{wk}$.

The following example illustrates the research dynamic as it was used in one SRI. The experiments shown were not demonstrations or in any way contrived. The teachers did these experiments themselves, motivated by peer interactions (including the author as scientist/mentor) and learning necessary techniques as they were needed. The interpersonal dynamics of the interactions are difficult to convey in the space available for this essay. Verbatim exchanges that illustrate such dynamics still require context and interpretation to mean anything. Dr. Robbie McCarty has already published such exchanges from a different SRI along with detailed contextual information, analysis, and interpretation (McCarty, 2003). Here, italicized passages are used to em- phasize the author's role in providing context according to Merton's three practices. These passages were not components of lectures or in any other respect one-sided. Rather, they were the author's contributions to sometimes extended discussions in which the teachers were full participants (McCarty, 2003). Note especially how the comments followed the history of the topic, how they always entailed an experiment, and how the experiments built up a coherent body of knowledge.

\section{Establishing the Phenomenon}

The chief SRI content focus was on genes, mutations, and heredity. Our scientific understanding of these phenomena has informed a coherent view of life's history on this planet that ranks among humanity's fundamental intellectual achievements (Dobzhansky, 1973; Ayala, 2008). Yet, despite their central importance, these phenomena are among the least well understood and poorly taught biology topics (Haury, 1996, and references therein).

Genetic variation within populations, arising chiefly from a combination of mutation and recombination, is the driving force of evolution and an indispensable concept for understanding it. As a phenomenon, it is easy to see variability in evident attributes just by looking at a room full of people, but there is no simple way to find out how much, if any, of this variability is genetic (i.e., heritable). Humans are clearly not the optimal experimental system to study this question. Mendel famously used pea plants to study stable genetic variants (mutants), but, as a monk, he had few distractions and enjoyed the luxury of time.

\section{Choosing the Experimental System}

What is called for is an organism that is easy and inexpensive to grow and maintain; one that replicates quickly; and, most important because we are interested in heritability, one where the progeny of individuals (or pairs of individuals) can be easily tracked. The history of biochemical genetics suggested that microorganisms, in particular bacteria or fungi, would be the optimal choice.

Wild-type strains of the harmless bacterium Escherichia coli are able to grow rapidly on a fully defined medium consisting of salts and glucose. These cells manufacture from these few components the thousands of compounds essential for their growth and replication. As each cell grows and divides, it forms a colony of cells just like itself. Each colony, containing $\sim 10^{8}$ progeny cells after $24-48 \mathrm{~h}$, is a clone derived from a single founder bacterium (Figure 1).

The compounds synthesized by the cells on minimal medium also can be supplied exogenously, as the cells have uptake mechanisms that spare them the necessity of synthesizing that which they can scavenge. Nutrients can be provided in a "rich" medium consisting of Campbell's Beef Broth added to the minimal medium (Figure 1). (This broth is similar in composition to standard microbiological media but is less expensive and easier to obtain.)

\section{Specifying Ignorance}

With these facts and observations in hand, the phenomenon of genetic variation could be redefined more precisely.

Suppose that the biosynthesis of each essential nutrient is genetically determined. Suppose further that different genes control the synthesis of different nutrients. It follows that if one such gene is altered so that the corresponding function is lost, mutant bac- 


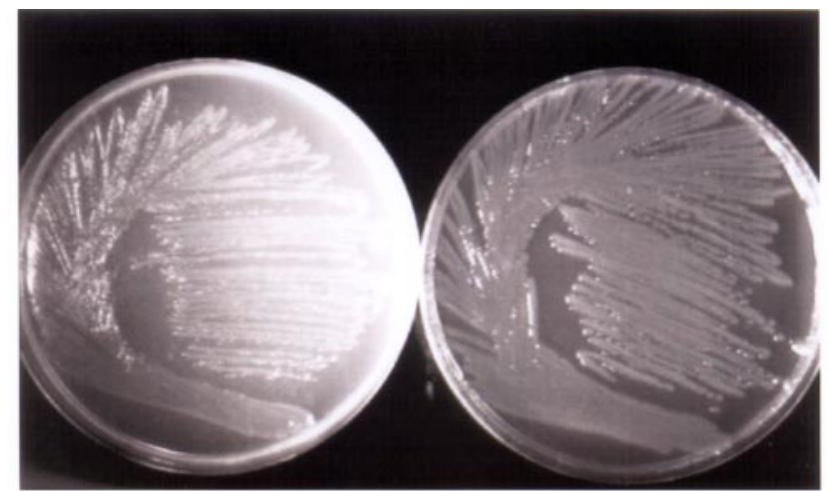

salts + dextrose (minimal medium)

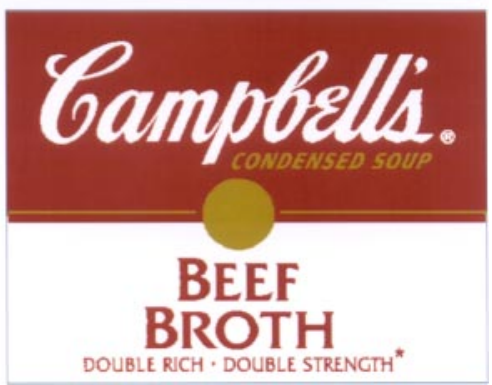

Figure 1. Bacteria can be nutritionally self-sufficient. A culture of E. coli strain W3110 was streaked on a minimal M9 salts plate (Miller, 1972) containing $0.2 \%$ dextrose (left) and a plate containing Campbell's soup medium. (Campbell's soup medium was prepared by diluting 1 can of Campbell's Beef Broth with 2 volumes of M9 salts and autoclaving or filter sterilizing. The growth rates of E. coli in this medium and in LB medium were comparable.) The plates were photographed after 18 - to 36 -h incubation at $37^{\circ} \mathrm{C}$.

teria would lose the ability to synthesize one and only one nutrient. This defect would not prevent growth on the rich medium, where all nutrients are provided exogenously, but it would on the glucose-salts minimal medium. Additionally, if there is genetic variation within a bacterial population, different cells will have lost the ability to synthesize different nutrients. Figure 1 indicates that most cells that can grow on the rich medium also can grow on the minimal medium, so any nutritional variants are likely to be rare. What we needed to do was figure out a general method to identify nutritional variants, if they exist, as cells able to form colonies on Campbell's soup but not on glucose-salts minimal medium plates.

One approach would be to test colonies arising on Campbell's soup plates for growth on minimal plates. This could easily be done with toothpicks, as the teachers had learned when they tested isolates of bacteria for antibiotic resistance earlier in the SRI.

However, whereas $10-100 \%$ of natural isolates proved to be antibiotic resistant, the frequency of nutritional variants might be much lower, making a colony-by-colony method problematic.

The author then suggested replica plating (Lederberg and Lederberg, 1952) as more suitable. UV light-irradiated cells grown overnight in Campbell's soup medium were used to prepare master plates containing $\sim 100$ colonies. By replica plating, all of these could be transferred in one step onto minimal medium plates (Figure 2), thereby increasing throughput by 2 orders of magnitude. Furthermore, the

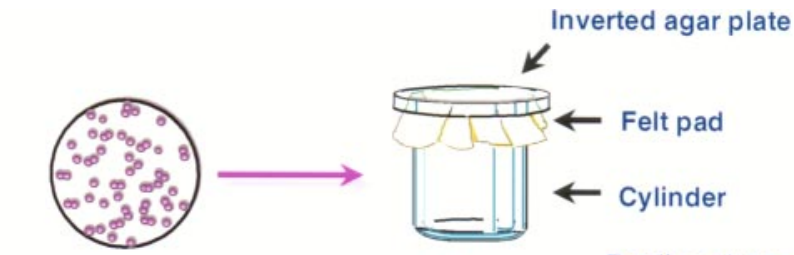

Campbell Soup agar plate with $\sim 100$ bacterial colonies (master plate)

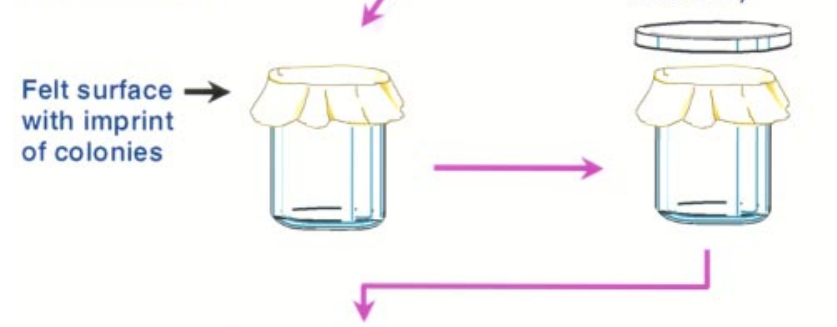

Incubate master \& replica plates

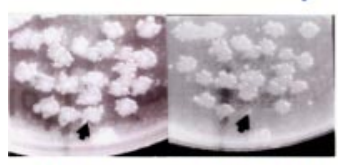

Soup
Minimal

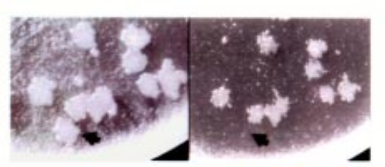

Soup
Replica plate: Fresh agar plate with minimal medium (salts/ dextrose)

Figure 2. Identification of nutritional mutants of E. coli by replica plating. Cells were grown and irradiated with $1000 \mathrm{ergs} / \mathrm{mm}^{2}$ of 254-nm light. Irradiated cell cultures were split immediately into several portions. Each portion (generally $0.5 \mathrm{ml}$ ) was diluted into 5 $\mathrm{ml}$ of Campbell's soup medium and grown overnight. Cell densities were determined by viable count and approximately 100 viable cells from each overnight were plated on Campbell soup plates and incubated $18 \mathrm{~h}$ at $34^{\circ} \mathrm{C}$ to allow individual cells to form colonies. The colonies were replica plated to M9 minimal medium plates by pressing each master plate against a felt pad secured to the top of a cylinder; this left an imprint of the colonies on the pad. The imprint was then replicated to a minimal medium plate, containing only salts and dextrose. After $24-\mathrm{h}$ incubation, the plates were compared to identify colonies that grew on the Campbell soup plate but not on the minimal plate. Each mutant was picked off the Campbell soup plate with a sterile toothpick and streaked onto a fresh Campbell soup plate. A single colony from this plate was streaked again for single colonies on a soup plate to ensure a pure culture.

frequency of mutations can be increased by induced mutagenesis, as with UV light irradiation.

Master and replica plates were incubated and then compared to identify colonies on the soup plate that were unable to grow on the minimal plate. Two such mutants are shown at the bottom of Figure 2 (arrowheads). Clearly, all the cells in the original population were not genetically identical; a few could grow on the rich medium but not the minimal medium.

The next level of specified ignorance was easily stated in the form of a prediction:

Each of the variants identified by replica plating should have lost the ability to synthesize one and only one nutrient supplied by Campbell's soup, and this nutrient should be different for different 


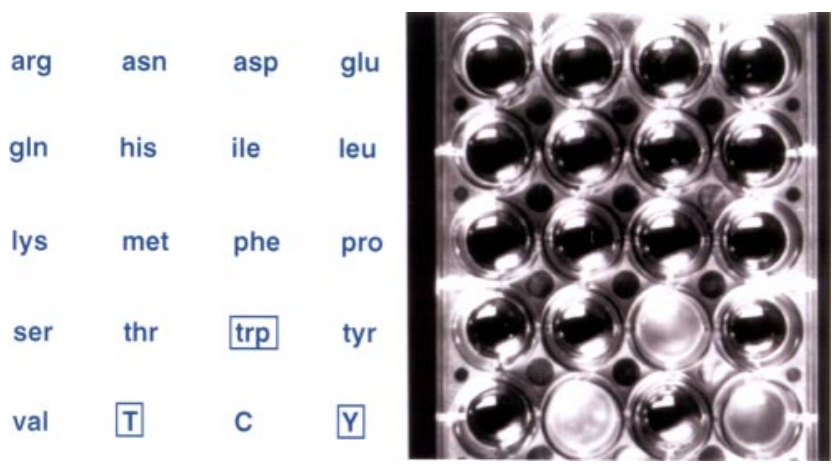

Figure 3. Screening nutritional variants of E. coli for nutritional Campbell's soup requirements. A mutant colony from the second plate (Figure 2) was picked with a sterile toothpick into $1 \mathrm{ml}$ of M9 salts in a sterile test tube. The solution was shaken vigorously to dislodge cells from the toothpick, which was then removed from the tube. A small volume of this suspension $(1 \mu \mathrm{l})$ was used to inoculate 1-2 ml of M9 minimal medium in the wells of a 24-well microtiter plate (Falcon 3047; available from Thermo Fisher Scientific, Waltham, MA). The minimal medium was supplemented with nutrients to be tested. For individual amino acids (indicated by threeletter code to the left of the plate), the final concentration in the well was $40 \mu \mathrm{g} / \mathrm{ml}$. For yeast extract $(\mathrm{Y})$, Bacto-tryptone $(\mathrm{T})$, or a vitaminfree acid hydrolysate of casein (C), the final concentration in the well was $2 \mathrm{mg} / \mathrm{ml}$. The plates were sealed with tape and incubated with gentle shaking for $24 \mathrm{~h}$ at $37^{\circ} \mathrm{C}$. Growth was determined by inspection for wells with bacterial growth, indicated by the scattered light from the turbid wells (boxed wells on the template). See the text for details.

variants. Although identifying a specific nutritional requirement seemed akin to finding a needle in a haystack, given the metabolic complexity of a cell, actually it is not. Many biosynthetic genes in bacteria are involved in the synthesis of the 20 naturally occurring amino acids. It therefore makes sense first to screen each mutant for its ability to grow in minimal medium supplemented with each of the 20 amino acids.

Each well of a 24-well microtiter plate contained minimal medium and one amino acid. Control wells contained no addition, yeast extract, an acid hydrolysate of casein, or an enzymatic digest of casein. Each well was then inoculated with a few mutant cells and the plate was incubated overnight (Figure 3).

Growth could be observed in only three wells. One contained the amino acid tryptophan. Thus, the mutation in this strain altered the biosynthesis of only a single nutrient, the amino acid tryptophan. This could be supplied in pure form, as shown, or as a complex mixture (Campbell's soup, yeast extract, or an enzymatic digest of casein). An apparent discrepancy was that the mutant was unable to grow in a medium supplemented with the amino acid mixture derived from casein by acid hydrolysis. However, acid hydrolysis is known to destroy tryptophan, so this result actually shows that all the amino acids except tryptophan will still not permit growth of the mutant; tryptophan and only tryptophan is required.

This mutation was designated trp-1. Another mutant, designated met-1, required methionine. A third, vit-1, did not require any amino acid but instead had lost the ability to synthesize an unspecified B vitamin (data not shown).

One of the teachers taught chemistry and chose to pursue a question related more to chemistry than to biology: Would the amount of exogenous tryptophan limit the growth of

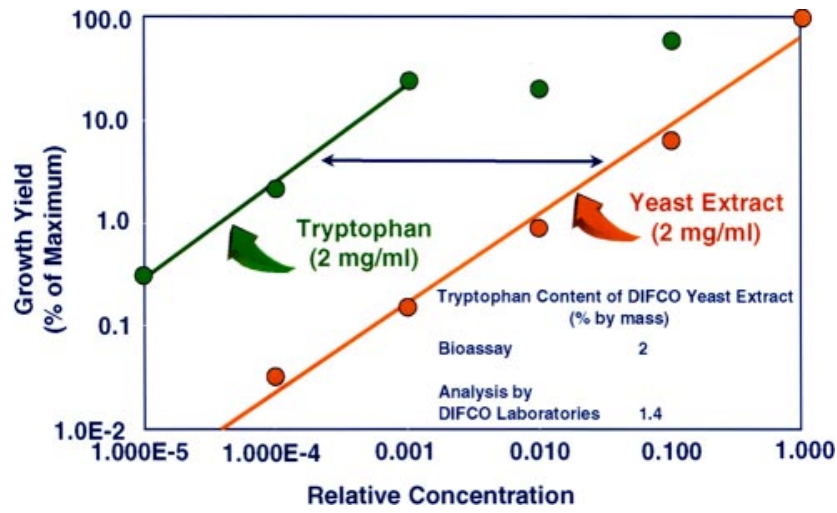

Figure 4. Quantitative analysis of tryptophan by bioassay. The $E$. coli trp-1 mutant (see Figure 3) was inoculated into microtiter wells as described in Figure 3. Wells contained the indicated dilution of L-tryptophan or of Bacto-yeast extract $(2 \mathrm{mg} / \mathrm{ml}$ stock solutions). After incubation at $37^{\circ} \mathrm{C}$, the extent of growth in each well was measured by the optical density at $600 \mathrm{~nm}$. The horizontal blue arrow indicates the mass fraction of tryptophan in the yeast extract, $\sim 2 \%$. The analysis of a different lot of yeast extract by Difco's own laboratory gave a mass fraction of $1.4 \%$ (inset).

trp-1 mutant cells and, if so, might the growth yield be used to measure the amount of tryptophan in an unknown sample? This teacher began with minimal medium supplemented with $2 \mathrm{mg} / \mathrm{ml}$ tryptophan and with serial 10-fold dilutions all the way down to $20 \mathrm{ng} / \mathrm{ml}$ tryptophan. Each medium was inoculated with a few mutant cells and the cultures were allowed to grow overnight. The teachers then measured the number of viable cells per milliliter as a function of tryptophan concentration (Figure 4).

At high concentrations of tryptophan, there was little effect of dilution. However, after the tryptophan had been diluted 1000fold, the number of viable cells was directly proportional to the amount of tryptophan added. Evidently, at the higher levels, there was enough tryptophan to support cell growth and division until something else became limiting or until toxic metabolic products accumulated. At lower levels, however, tryptophan itself limited growth.

To test whether the growth yield of bacteria might be used to determine the concentration of exogenous tryptophan, the teacher used a commercial preparation of yeast extract from Difco (Detroit, MI). (Crushed and water-extracted yeast pills from a supermarket or health food store also should work.) The experiment was otherwise identical to that with pure tryptophan (Figure 4).

With yeast extract the number of viable cells diminished even at the first dilution, indicating that tryptophan was already limiting. As the yeast extract was diluted further, the teacher observed a good linear relationship between the amount of yeast extract and the yield of cells. Furthermore, the slope of the curve was identical to that with pure tryptophan, indicating that the efficiency of tryptophan utilization was the same as that with pure tryptophan. The teacher could therefore determine the tryptophan content of yeast by how far to the right the curve was shifted relative to pure tryptophan (Figure 4, horizontal blue arrow).

The data indicated that the yeast extract contained $\sim 2 \%$ tryptophan by mass. We obtained an analysis of an unspecified lot of yeast extract from Difco. Their value for trypto- 
phan was $1.4 \%$, within experimental error and uncertainty about the lot number Difco analyzed.

\section{Authenticity}

An important OSP goal was that experiments should be authentic. At the outset, "authentic" had an historical slant referring largely to the experiments themselves. It described OSP experiments chosen because of the important roles they played in the development of a scientific discipline. Thus, experiments very like those of Figures 2 and 3 were foundational to the field of biochemical genetics and won George Beadle and Ed Tatum the 1958 Nobel Prize in Physiology or Medicine. Joshua Lederberg, who invented replica plating, won along with Tatum and Beadle, albeit for experiments not discussed here. And bioassays like that shown in Figure 4 were used to identify and isolate essential bacterial growth factors (Snell et al., 1939). In this sense, "authentic" could be opposed to "contrived."

In time, authentic took on an additional, pedagogical meaning, referring to the OSP experience as a whole, independent of specific content and conforming in so far as possible to the research dynamic. Thus, other SRIs have addressed viruses (Silverman, 2003), gene regulation, mutagenesis, and antibiotic resistance. All of them incorporated simple, transparent gateway experiments coupled to specified ignorance through peer interactions.

\section{EVALUATION}

All indications are that the research dynamic has a significant positive effect on teachers and that this effect spills over into their classroom performance. In 1999, a survey was sent to 19 participating teachers (Harris et al., 2000 and unpublished data); 15 responded (three of the remaining four had left the profession). The survey consisted of 36 closed-end and three open-ended questions (Harris et al., 2000). One of the former questions was especially informative because it documented a marked shift in teachers' attitudes about themselves as science educators after participation. Seven of the 15 respondents reported a shift from "very well prepared" to "extremely well prepared" and two from "somewhat well prepared" to "very well prepared" (Table 1). We

Table 1. Effect of the summer course on teachers' self-perception of preparedness $^{\mathrm{a}}$

\begin{tabular}{lcccc}
$\begin{array}{c}\text { How prepared were you } \\
\text { to teach science }\end{array}$ & Not at all & Somewhat & Very & Extremely \\
\hline $\begin{array}{c}\text { Before the summer } \\
\text { course? }\end{array}$ & $0(0)$ & $2(2)$ & $12(24)$ & $1(3)$ \\
$\begin{array}{c}\text { After the summer } \\
\text { course? }\end{array}$ & $0(0)$ & $0(0)$ & $7(14)$ & $8(24)$ \\
\end{tabular}

\footnotetext{
${ }^{a}$ Number of teachers (score). The score was calculated by assigning one point for "somewhat prepared," two for "very prepared," and three for "extremely prepared." Paired "before-and-after" values were analyzed by the Wilcoxon signed rank test $\left(\mathrm{W}_{+}=45\right)$. For $\mathrm{n}=$ $15, \operatorname{Pr}\left(\mathrm{H}_{\mathrm{O}}\right)<5 \times 10^{-3}$.
}

interpret this shift as reflecting positive effects on teacher confidence.

A second source of formative evaluation has been teachers' many informal and unsolicited communications to the author. Some of these are collected in Table 2 as pertaining to teaching practices, confidence/motivation, and student performance. Collectively, these comments indicate that insight gained from the research dynamic does spill over into the classroom. Teachers' requests for materials, supplies, and advice during the school year support this conclusion.

Finally, as noted, Dr. Robbie McCarty has published a detailed study of the OSP (McCarty, 2003). She concluded that.

"[t]he main strength of the OSP lies in the model of learning that it presents. Experiential learning in a state of relaxed alertness is indeed the optimal environment for individuals to acquire knowledge at the deepest level of being. Discovering the biological principles involved in understanding genes, mutation and heredity in the same sequence as the original researchers is not a manipulation; the data collected and the questions that come to mind as one engages in these explorations flow as naturally today as they did then. For this reason utilizing experiments and techniques that literally laid the foundation for the new science of molecular biology, and therefore have historical significance, is outstanding; the fact that these same experiences provide the stuff for building intellectual bridges between the past and the cutting-edge science of today is genius."

"Another strength of the OSP lies in the project director's responsiveness to the teachers. Silverman clearly desires to assist these teachers in transforming themselves, and their own classrooms, rather than prescribing what teachers should do. It is this attitude that makes the partnership full, and goes a long way to assure the success of the program."

McCarty also considered three weaknesses:

"... fuller advantage could be taken of the cadre of mentor teachers that the OSP has established... The program needs to continue to collect teacher-reported data, and certainly [to] construct individual case studies for each teacher. Although there is some teacher-reported information about student learning in the classroom, and certainly documented cases of students having success with science fair projects, there [are] no hard data to document an increase in student conceptual knowledge and/or attitudes about the nature of scientific endeavor."

\section{SUMMARY AND FUTURE DEVELOPMENTS}

The OSP research dynamic emerged over time. Its elements were there all along, but they took time to integrate into a coherent learning model for high school science teachers. This model also should work beautifully with adolescents in the classroom. However, as emphasized by McCarty (2003), this assumption remains largely untested. Some teachers do use gateway experiments in their classrooms, as evidenced by requests for materials, equipment, and advice. However, understanding the full potential of the research dynamic will require collaborative efforts among teachers, other education professionals, and scientists. Such efforts are the logical and certainly the most important next step.

The need for further elaboration, application, and evaluation of the research dynamic does not reduce its present 
Table 2. Unsolicited teacher comments received by the author ${ }^{\mathrm{a}}$

\section{Teaching practices}

"... as I learned last Summer, true science is much more than just learning concepts and techniques. True science is solving problems and sometimes not solving problems. It is openended and frustrating and completely addictive. True science is something every science teacher should be trying to teach. Science is about the process and not just the content."

"He [a collaborator] and I have two hours during which we can link up and share labs... (we're both beginning biochem discussions next week ... so we'll be ready to do the enzyme studies in the next couple of weeks."

"I hope to spend more time in the lab than ever before.... we [referring to a collaborator; see previous quote] are working out a time to use the video [videoconferencing] to do some labs ... we are going to do the enzyme lab together."

"Once you start teaching using OSP, you will never teach the same way again."

\section{Confidence/motivation}

"A very big part of this success [student science fair projects] is the fact that I was motivated by the experience last summer and I have been more successful in motivating my students and colleagues."

[Referring to an experiment,] "it worked beautifully. Can you believe it?! It worked the first time! I guess it pays to do it over and over before you try it with students...."

"There is no substitute for hands-on experience. Since arriving home, I have been reading through notes I took during previous Summer institutes. I was astounded to find information on diauxic curves, lac-operon, and antibiotic resistance. The concepts had been introduced in lectures but without practical experience, I had forgotten the terms and am certain I had little understanding at the time."

Student performance

"Setting an ultimate goal of isolating, identifying and learning all we can about a local virus has given my students an incentive to fully understand the basic concepts and techniques required to accomplish this goal. Giving them a final direction, rather than what seems to be unrelated bits and pieces of data, has pulled them together ... I am elated!... If you can change the perspective of ONE teacher...., you can stimulate the minds of MANY students."

"I have some students working on the microbes for the past week or so and I thought I would give you an update. They are really having a GOOD TIME! One of the students brought in some water from his fish tank and we did the "selection" activity with Tetracycline. We had about a hundred [tet-resistant] colonies. ... It turns out that they had been using tet in the tank to try to clear up an 'epidemic' which had been killing their fish! So, my students are really excited!"

"My students experienced a new level of science instruction. I believe they sensed a new freedom to think outside the box... I saw new levels of creativity with my students and myself."

"In my level one biology class, it [research dynamic] is a question and discussion generator."

"I did not realize this would generate such interest and excitement with the students. I knew that it could be useful, but I think it will have an even bigger impact on my classes than I anticipated."

"The students are very inquisitive! One student in particular had all of the 'right' questions! You could certainly tell she was doing some critical thinking. And she wasn't the only one!"

${ }^{a}$ From Silverman (2005). value to precollege science teachers. SRIs can still be a transformative experience, changing the way science teachers teach, irrespective of what specific approaches they use in their classrooms. This alone is a signal achievement.

\section{ACKNOWLEDGMENTS}

I thank Dr. William G. Thurman, Vernon Cook, and Frank Merrick for unflagging support and encouragement. I am indebted to Dawna Schweitzer, Jan Cherry, and Deborah Cornelison, the teachers who carried out all the experiments described here, and to all the other OSP participants over the years. Two anonymous reviewers' comments measurably improved the essay. This work was supported by grants from the Howard Hughes Medical Institute, from the Merrick Foundation and The Williams Companies, and by the scientific resources of the Oklahoma Medical Research Foundation.

\section{REFERENCES}

Ayala, F. (2008). Science, evolution, and creationism. Proc. Natl. Acad. Sci. USA 105, 3-4.

Bloom, P., and Weisberg, D. (2007). Childhood origins of adult resistance to science. Science 316, 996-997.

Carey, S. (1986). Cognitive science and science education. Am. Psychol. 41, 1123-1130.

Clough, E., and Wood-Robinson, C. (1985). Children's understanding of inheritance. J. Biol. Educ. 19, 304-310.

Dobzhansky, T. (1973). Nothing in biology makes sense except in the light of evolution. Am. Biol. Teach. 35, 125-129.

Donovan, M., and Bransford, J. (2005). Pulling threads. In: How Students Learn: History, Mathematics and Science in the Classroom, ed. M. Donovan and J. Bransford, Washington, DC: National Academies Press, 569-589.

Duschl, R. (1989). A framework for reapplying history and philosophy of science to science education. ERIC Document Reproduction Service No. ED 320782

Egan, K. (1997). The Educated Mind: How Cognitive Tools Shape Our Understanding, Chicago, IL: The University of Chicago Press.

Feynman, R. (1998). The Meaning of It All: Thoughts of a CitizenScientist, Reading, MA: Addison-Wesley.

Hanauer, D., Jacobs-Sera, D., Pedulla, M., Cresawn, S., Hendrix, R., and Hatfull, G. (2006). Teaching scientific inquiry. Science 314, $1880-1881$.

Harris, R., Green, M., Frisby, D., and Wendling, B. (2000). The Oklahoma Science Project: does it provide worthwhile tools to Oklahoma's science teachers? J. Okla. Assoc. Teach. Educ. 4, 46-53.

Haury, D. (1996). Teaching evolution in school science classes. ERIC Digest. www.ericdigests.org/1998-1/evolution.htm. (accessed 16 March 2009).

Johnson, G. (2008). The Ten Most Beautiful Experiments, New York: Alfred A. Knopf.

Kindfield, A. (1991). Confusing chromosome number and structure: a common student error. J. Biol. Educ. 25, 193-200.

Lederberg, J., and Lederberg, E. (1952). Replica plating and indirect selection of bacterial mutants. J. Bacteriol. 63, 399-406.

Leslie, M. 2001. Scientific outliers. HHMI Bull. 14, 26-29.

McCarty, R. (2003). Specified ignorance: a pedagogical and cognitive tool for learning the nature and process of science. Teach. Learn. $17,113-132$. 
Merton, R. (1987). Three fragment's from a sociologist's notebook. Annu. Rev. Sociol. 13, 1-28.

Miller, J. (1972). Experiments in Molecular Genetics, Cold Spring Harbor, NY: Cold Spring Harbor Laboratory Press.

Pedulla, M. et al. (2003). Origins of highly mosaic mycobacteriophage genomes. Cell 113, 171-182.

Pine, K. et al. (2001). Children's misconceptions in primary science: a survey of teachers' views. Res. Sci. Tech. Educ. 19, 79-96.

Posner, G., Strike, K., Hewson, P., and Gertzog, W. (1982). Accommodation of a scientific conception: toward a conceptual change. Sci. Educ. 66, 211-227.

Schwartz, R., and Lederman, N. (2007). What scientists say: scientists views of nature of science and relation to science context. Int. J. Sci. Educ. 30, 727-771.

Schwartz, R., Lederman, N., and Crawford, B. (2004). Developing views of nature of science in an authentic context: an explicit approach to bridging the gap between nature of science and scientific inquiry. Sci. Teach. Educ. 88, 610-645.
Seago, J. (1992). The role of research in undergraduate education. Am. Biol. Teach. 54, 401-405.

Shamos, M. (1995). The Myth of Scientific Literacy, New Brunswick, NJ: Rutgers University Press, 199.

Silverman, P. M. (2003). The origins of molecular biology: a pedagogical tool for the professional development of pre-college science teachers. Biochem. Mol. Biol. Educ. 31, 1-6.

Silverman, P. M. (2005). The Oklahoma Science Project for professional development: a road taken. In: ed. Yager, R., Exemplary Science: Best Practices in Professional Development, Arlington, VA: NSTA Press, 161-170.

Snell, E., Strong, F., and Peterson, W. (1939). Growth factors for bacteria. VIII. Pantothenic and nicotinic acids as essential growth factors for lactic and propionic acid bacteria. J. Bacteriol. 38, 293308

Witte, M. (2008). Joshua Lederberg's interest in ignorance. Science 320,1159 . 